\title{
iStent Trabecular Micro-Bypass Stent Implantation with Cataract Surgery in a Japanese Glaucoma Population
}

This article was published in the following Dove Press journal: Clinical Ophthalmology

\author{
Koji Nitta $\mathbb{D}^{\prime}$ \\ Yutaro Yamada' \\ Satomi Morokado' \\ Kazuhisa Sugiyama ${ }^{2}$ \\ 'Department of Ophthalmology, Fukui- \\ Ken Saiseikai Hospital, Fukui, Fukui \\ Prefecture, Japan; ${ }^{2}$ Department of \\ Ophthalmology, Kanazawa University, \\ Kanazawa, Ishikawa Prefecture, Japan
}

Introduction: This study assesses two-year efficacy and safety following implantation of a single trabecular micro-bypass stent (iStent ${ }^{\circledR}$ ) with concomitant phacoemulsification cataract surgery in Japanese patients with open-angle glaucoma (OAG).

Materials and Methods: This retrospective, consecutive case series included eyes that underwent iStent implantation with phacoemulsification and were followed for 24 months postoperative. Efficacy and safety measures included intraocular pressure (IOP), number of glaucoma medications, adverse events, secondary surgeries, visual fields, and endothelial cell counts.

Results: Of 73 operated eyes, 53 eyes had 24 months of follow-up and are analyzed. Diagnoses included primary open-angle glaucoma (POAG, $n=25)$, normal-tension glaucoma (NTG, $n=16$ ), and pseudoexfoliative glaucoma ( $\mathrm{PXG}, \mathrm{n}=12$ ). At 24 months, mean IOP reduced by $18 \%$ to 13.6 $\pm 3.0 \mathrm{mmHg}$ versus $16.5 \pm 3.4 \mathrm{mmHg}$ preoperatively $(\mathrm{p}<0.0001$ ), and mean medication number reduced by $81 \%$ to $0.37 \pm 0.74$ versus $1.96 \pm 0.98$ preoperatively $(\mathrm{p}<0.0001)$. The percentage of medication-free eyes was $77 \%$ versus $0 \%$ preoperatively, and $81 \%$ of eyes had IOP $\leq 15 \mathrm{mmHg}$ versus $42 \%$ preoperatively. Results were similarly favorable across glaucoma subtypes (POAG, NTG, PXG). Notably, mean IOP in NTG eyes decreased to $12.8 \pm 1.4 \mathrm{mmHg}$ from $14.4 \pm 3.0$ $\mathrm{mmHg}$ preoperatively $(\mathrm{p}=0.03$ ), and medications decreased by $87 \%$ to $0.31 \pm 0.70$ versus 2.38 \pm 0.72 preoperatively ( $\mathrm{p}<0.0001$ ). At 24 months, $81 \%$ of NTG eyes were medication-free (versus $0 \%$ preoperatively); 2 NTG eyes $(13 \%)$ were on $\geq 2$ medications (versus $100 \%$ preoperatively). Throughout the follow-up, visual fields and endothelial cell counts remained stable; 1 eye (1.9\%) underwent filtration surgery.

Discussion: Favorable safety and significant IOP and mediation reductions were achieved through two years following iStent implantation with phacoemulsification in a Japanese population. These gains were achieved across all glaucoma subtypes (including POAG, NTG, PXG).

Conclusion: This real-world study supports the viability of iStent implantation to treat Japanese patients with glaucoma and shows that the benefits extend to those with NTG or PXG in addition to POAG.

Keywords: microinvasive glaucoma surgery, MIGS, iStent, trabecular micro-bypass, Japanese, normal-tension glaucoma

\section{Introduction}

Glaucoma is a leading cause of vision loss worldwide and a considerable clinical challenge for physicians and patients alike. Current approaches to treatment are aimed at reduction of intraocular pressure (IOP), the sole modifiable risk factor associated with the disease. ${ }^{1,2}$ Open-angle glaucoma (OAG), the most common
Fukui-Ken Saiseikai Hospital, Funabashi 7-I, Wadanaka-Cho, Fukui City, Fukui 9|8-8503, Japan

Tel +8I 77623 IIII

Email nitta.koji700I@fukui.saiseikai.or.jp 
form of glaucoma, is typically only minimally symptomatic until the late stages of the disease, and thus up to $50 \%$ of people are estimated to be unaware of their diagnosis and are not receiving treatment. ${ }^{3,4}$ Normal-tension glaucoma (NTG), a variant of OAG, is characterized by glaucomatous damage despite IOP values being in the normal range. Since elevated IOP historically was considered integral to diagnosing glaucoma, normotensive NTG eyes are frequently underdiagnosed or undertreated. Despite their normal IOP values, NTG eyes remain reliant on IOP reduction as a cornerstone of their treatment, as established in the landmark Collaborative Normal-Tension Glaucoma Study (CNTGS). ${ }^{5}$

IOP reduction may be achieved by medical or surgical means. Treatments range from conservative, topical medications to more aggressive filtration surgeries. Between these two ends of the spectrum, micro-invasive glaucoma surgery (MIGS) has filled a critical treatment gap. ${ }^{6}$ This growing class of procedures has altered the treatment paradigm, introducing a micro-invasive surgical intervention earlier in the disease process, particularly in those with concomitant cataract who already are undergoing surgery.

The iStent ${ }^{\circledR}$ (Glaukos Corp.), the first US Food and Drug Administration (FDA)-approved MIGS implant, and the more recently introduced iStent inject (containing two stents, each with updated design), are trabecular microbypass stents designed to augment physiologic aqueous outflow in order to lower IOP. They have been studied extensively and are established as a safe and effective option in various types of OAG with and without concomitant cataract surgery. ${ }^{7-40}$ However, relatively few studies have been completed in Japanese patients ${ }^{11,23}$ or in NTG. ${ }^{24,25}$

Japanese populations have a significantly higher prevalence of NTG than most other populations, accounting for $>90 \%$ of OAG cases in Japan. ${ }^{41}$ NTG presents a challenge for glaucoma treatment, particularly with respect to MIGS devices, because it can be difficult to lower IOP below episcleral venous pressure (EVP) with current MIGS procedures involving the physiologic trabecular outflow pathway. ${ }^{42}$ Even if IOP reductions are modest, however, every $1 \mathrm{mmHg}$ drop in IOP has been shown to be meaningful for reducing glaucomatous progression, ${ }^{1}$ and IOP reduction remains the mainstay of treatment for NTG. ${ }^{5}$ iStent's mechanism of action is to reduce aqueous outflow resistance at the level of the trabecular meshwork, so the device can be expected to reduce IOP and serve as a viable treatment option for NTG just as it has in other glaucoma subtypes. To date, there are relatively limited data available regarding the role of the trabecular microbypass stent in either NTG or Japanese populations. The present real-world case series sought to address this gap in clinical knowledge by analyzing the outcomes of iStent trabecular micro-bypass implantation with cataract surgery in a Japanese population, including subgroup analyses of eyes with POAG, NTG, and PXG.

\section{Methods}

\section{Study Design}

This retrospective consecutive case series included patients with a preoperative diagnosis of OAG (including POAG, NTG, or PXG), implantation with a single trabecular micro-bypass stent with concomitant cataract surgery, and 24 months of follow-up data. All procedures were performed by a single surgeon (K. Nitta) at Fukuiken Saiseikai Hospital in Fukui, Japan. Ethics Committee approval was obtained from the Institutional Review Board (IRB) of the Fukui-ken Saiseikai Hospital (Fukui, Japan). All procedures performed were in accordance with the 1964 Declaration of Helsinki and its later amendments or comparable ethical standards. Informed consent was obtained from all participants.

\section{Surgical Technique and Postoperative Management}

The standard surgical technique was utilized, ${ }^{7}$ which may be summarized as follows. Following phacoemulsification cataract surgery, the surgeon advances the iStent inserter through the existing phacoemulsification incision to the nasal angle, then implants the stent through the trabecular meshwork into Schlemm's canal. The stent itself is a single-piece, titanium, heparin-coated, L-shaped device measuring $1.0 \mathrm{~mm}$ in length, $0.33 \mathrm{~mm}$ in height, and possessing a snorkel bore diameter of 120 $\mu \mathrm{m}$. By creating a patent pathway from the anterior chamber (where the snorkel resides) into Schlemm's canal (where the outlet resides), the stent is designed to enhance aqueous outflow and thereby reduce IOP. Following surgery, patients received both topical antiinflammatory medication (Bromfenac Sodium Hydrate Ophthalmic Solution $0.1 \%$, two times daily) and topical antibiotic (Levofloxacin Ophthalmic Solution 1.5\%, four times daily) for 4 weeks. 


\section{Outcome Measures and Safety Evaluation}

The main efficacy outcomes in the study were IOP (via Goldmann applanation tonometry $100 \%$ of the time) and number of ocular hypotensive medications. Preoperative data were collected from the visit immediately prior to the procedure to establish a baseline; patients were still on their medications at the time of the preoperative visit (ie, no washout). Postoperative data were collected from patients monthly from months 1 to 6 , and every three months thereafter. All patients were instructed to stop their glaucoma medications immediately (within 24 hours) before surgery. After surgery, medication was reintroduced if the IOP exceeded the preoperative medicated IOP at two consecutive visits. A safety profile was characterized by noting operative complications, adverse events, secondary glaucoma surgeries, visual fields, and endothelial cell counts.

\section{Statistical Analyses}

Descriptive statistics (mean and standard deviation) were used to summarize IOP and number of medications from the preoperative visit through 6 months postoperatively. Proportional analyses were completed for percent of eyes with $\mathrm{IOP} \leq 18 \mathrm{mmHg}$ or $\mathrm{IOP} \leq 15 \mathrm{mmHg}$; and proportion of eyes on 0 or $\geq 2$ medications. A paired $t$-test was used to compare preoperative versus month 24 mean IOP and medications. Results are reported for the entire cohort as well as stratified by glaucoma subtype (POAG, NTG, PXG). A p-value of $<0.05$ was considered statistically significant.

\section{Results}

\section{Subject Demographics}

Of 73 operated eyes, 53 eyes had reached 24 months of follow-up and are analyzed. Diagnoses included 25 eyes with POAG, 16 eyes with NTG, and 12 eyes with PXG; mean age was 73 years and average baseline visual field mean deviation $(\mathrm{MD})$ was $-8.1 \pm 4.6$. No eyes had a history of prior glaucoma surgery or laser procedures, in accordance with Japanese guidelines for iStent usage. Complete demographic and baseline parameters are shown in Table 1.

\section{IOP and Medications}

Figure 1 displays the mean IOP for the overall cohort from the preoperative visit through 24 months postoperative, and Figure 2 shows proportional analyses for IOP at the
Table I Demographic and Preoperative Ocular Parameters

\begin{tabular}{|l|l|l|}
\hline \multicolumn{3}{|l|}{ Parameter ( $\mathbf{n = 5 3}$ eyes) } \\
\hline Age (years) & Mean \pm SD & $73.4 \pm 9.1$ \\
Eye & right/left & $42 / 31$ \\
Glaucoma subtype & POAG & $47 \%(25 / 53)$ \\
$\%(n)$ & NTG & $30 \%(16 / 53)$ \\
& PXG & $23 \%(12 / 53)$ \\
IOP (mmHg) & Mean \pm SD & $16.5 \pm 3.4$ \\
Number of medications & Mean \pm SD & $1.96 \pm 0.98$ \\
Medication burden & 0 meds & $0 \%(0 / 53)$ \\
$\%(n)$ & $\geq 2$ meds & $62 \%(33 / 53)$ \\
Visual field MD (dB) & Mean \pm SD & $-8.1 \pm 4.6$ \\
\hline
\end{tabular}

Abbreviations: IOP, intraocular pressure; SD, standard deviation; POAG, primary open-angle glaucoma; NTG, normal-tension glaucoma; PXG, pseudoexfoliative glaucoma; MD, mean deviation; med, medication.

preoperative and 12- and 24-month visits. At baseline, the mean IOP was $16.5 \pm 3.4 \mathrm{mmHg}$, with $75 \%$ of eyes having IOP $\leq 18 \mathrm{mmHg}$ and $42 \%$ of eyes having IOP $\leq 15 \mathrm{mmHg}$. At 24 months after surgery, the mean IOP had reduced by $18 \%$ to $13.6 \pm 3.0 \mathrm{mmHg}(\mathrm{p}<0.0001), 87 \%$ of eyes had IOP $\leq 18 \mathrm{mmHg}$, and $81 \%$ of eyes had IOP $\leq 15 \mathrm{mmHg}$.

Figure 3 shows the mean number of medications for the overall cohort from the preoperative visit through 24 months postoperative, and Figure 4 shows proportional analyses of medication burden at the preoperative and 12- and 24-month visits. There was a significant reduction in medication burden after surgery: preoperatively, eyes were on a mean of $1.96 \pm 0.98$ medications, no eyes were medication-free, and $62 \%$ of eyes were on $\geq 2$ medications; at 24 months postoperative, there was an $81 \%$ medication reduction to $0.37 \pm 0.74$ medications $(\mathrm{p}<0.0001), 77 \%$ of eyes were medication-free, and $12 \%$ of eyes were on $\geq 2$ medications (Figure 4).

Results also were analyzed by glaucoma subtype (Figures 5-7) and revealed similarly favorable outcomes in eyes with POAG, NTG, and PXG. In eyes with POAG $(n=25)$, the mean IOP was reduced by $20 \%$ to $14.9 \pm 3.3$ $\mathrm{mmHg}$ versus $18.6 \pm 2.9 \mathrm{mmHg}$ at baseline $(\mathrm{p}<0.001)$, and medication use decreased by $82 \%$ to $0.33 \pm 0.76$ medications versus $1.88 \pm 1.13$ preoperatively $(\mathrm{p}<0.001)$. In NTG eyes $(n=16)$, in which the primary goal of surgery was the reduce medication burden (and secondarily to maintain or reduce IOP), mean number of medications decreased by $87 \%$ to $0.31 \pm 0.70$ medications versus $2.38 \pm 0.72$ preoperatively $(p<0.0001)$. At 24 months, $81 \%$ of NTG eyes were medication-free versus $0 \%$ preoperatively, and 2 NTG eyes $(13 \%)$ were on $\geq 2$ medications versus $100 \%$ preoperatively. Meanwhile, the mean IOP in NTG eyes 


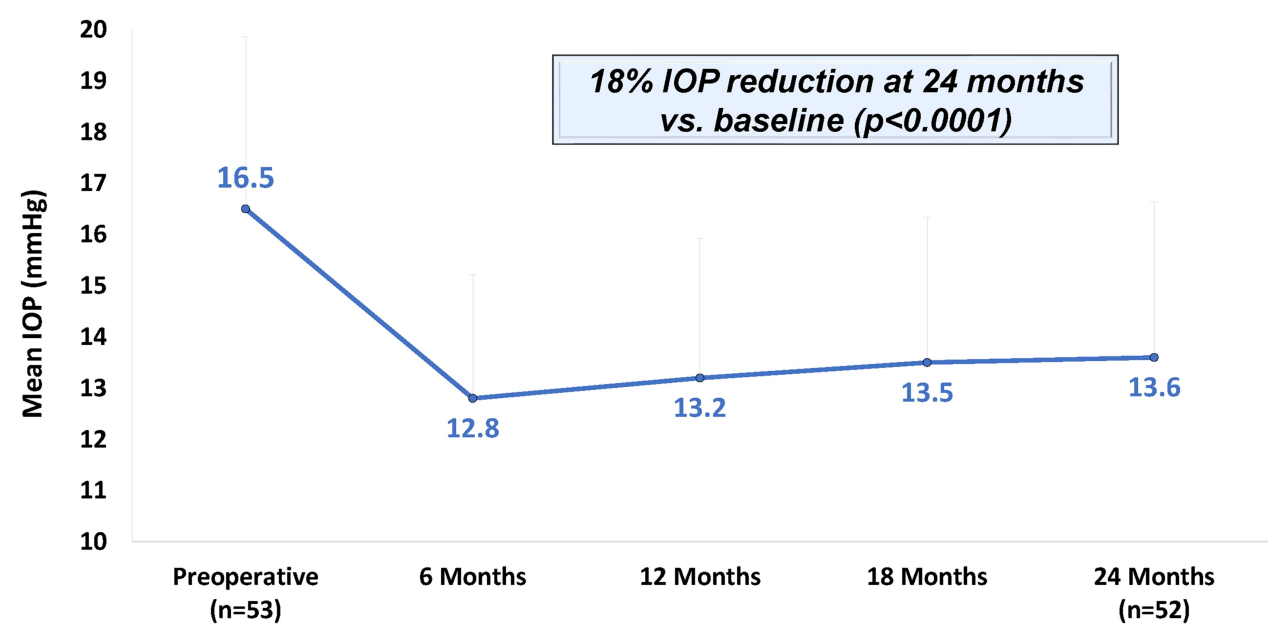

Figure I Mean intraocular pressure through 24 months postoperative* all glaucoma subtypes.

Abbreviations: IOP, intraocular pressure; Vertical bars represent standard deviation. *I eye had filtration surgery at 3 weeks postoperative; subsequent IOP values are excluded from analysis above.

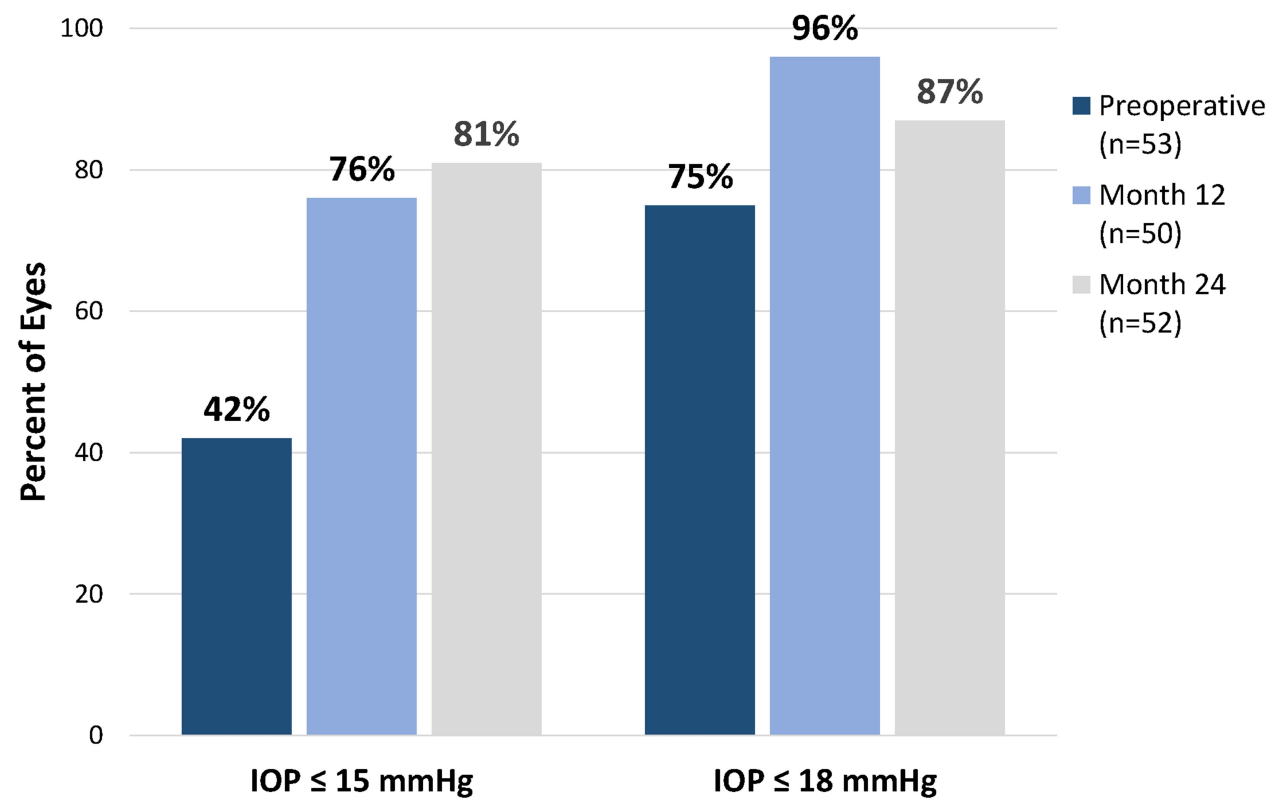

Figure 2 Proportional analysis of IOP preoperatively and at 12 and 24 months postoperative* all glaucoma subtypes.

Abbreviations: IOP, intraocular pressure; $* I$ eye had filtration surgery at 3 weeks postoperative; subsequent IOP values are excluded from analysis above.

was reduced by $11 \%$ to $12.8 \pm 1.4 \mathrm{mmHg}$ at 24 months versus $14.4 \pm 3.0 \mathrm{mmHg}$ preoperatively $(\mathrm{p}=0.03)$. In eyes with PXG ( $\mathrm{n}=12)$, baseline IOP was $15.0 \pm 2.0 \mathrm{mmHg}$ and decreased by $19 \%$ to $12.1 \pm 3.2 \mathrm{mmHg}(\mathrm{p}=0.003)$ at 24 months postoperative. Medication use was reduced by $68 \%$ to $0.50 \pm 0.80$ versus $1.58 \pm 0.79$ at baseline $(\mathrm{p}=0.005)$.

\section{Safety Profile}

All eyes were implanted with one iStent following cataract surgery. One intraoperative adverse event was noted (slightly diagonal stent insertion); however, the lumen remained patent, there was no iris or endothelial touch nor cyclodialysis, and no intervention nor sequelae occurred. Subsequent postoperative IOP through 24 months in this eye ranged from 14 to $16 \mathrm{mmHg}$ on 0 medications (versus baseline IOP of $23 \mathrm{mmHg}$ on 1 medication). Postoperatively, adverse events included 4 cases of microhyphema or mild hyphema, which resulted in no intervention; 2 cases of stent occlusion from the iris, which appeared at 2 and 5 months postoperatively and were managed with careful observation and stent repositioning, 
2.5

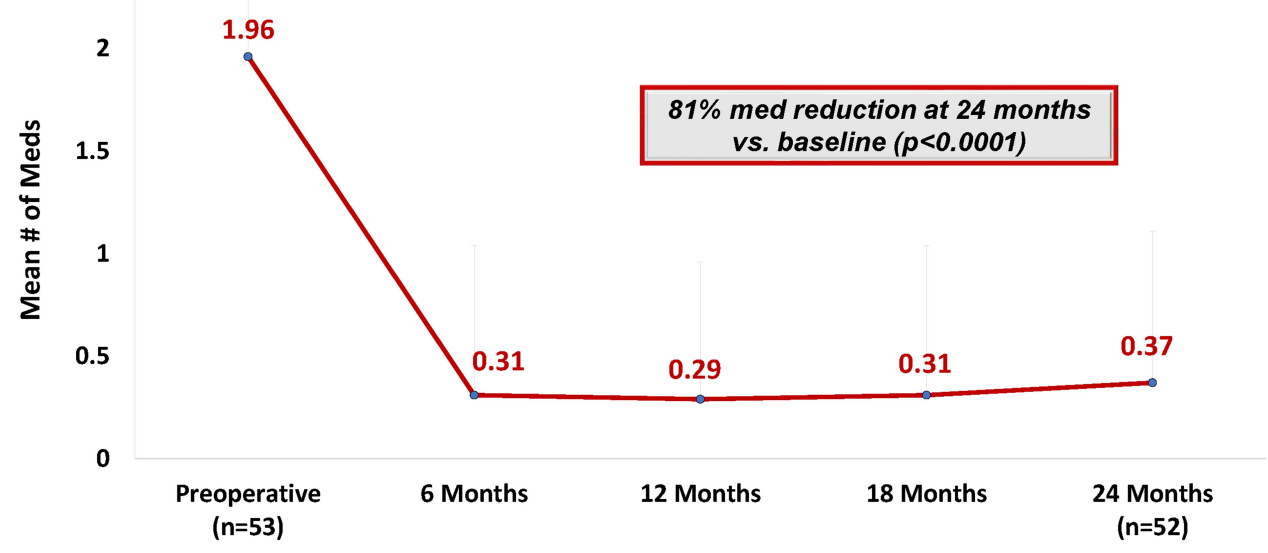

Figure 3 Mean number of medications through 24 months postoperative* all glaucoma subtypes.

Abbreviations: Meds, medications; Vertical bars represent standard deviation. *I eye had filtration surgery at 3 weeks postoperative; subsequent medication values are excluded from analysis above.

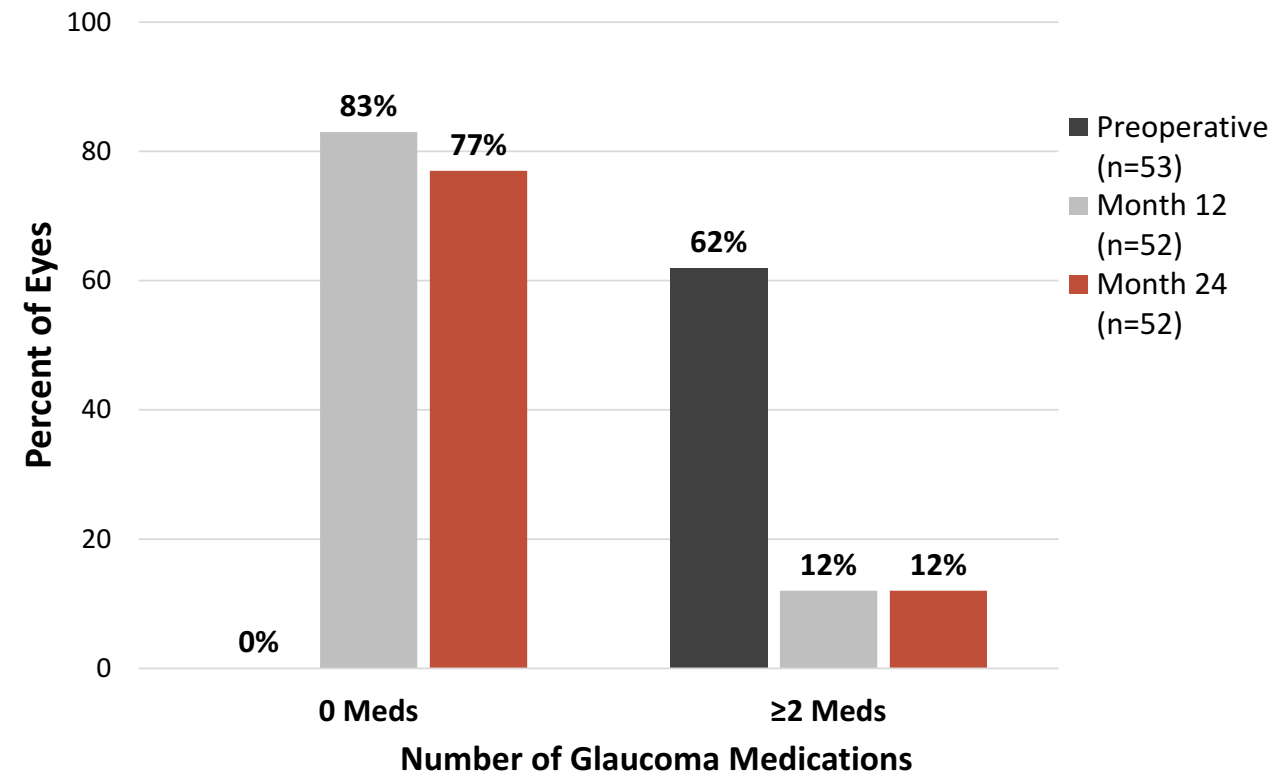

Figure 4 Proportional analysis of medications preoperatively and at 12 and 24 months postoperative* all glaucoma subtypes.

Abbreviations: Meds, medications; *I eye had filtration surgery at 3 weeks postoperative; subsequent medication values are excluded from analysis above.

respectively, with no noted sequelae; and 6 cases of IOP elevation within 1 month postoperative which were managed with careful observation (1 case), topical medication and/or hyperosmotic drip (4 cases), or filtration surgery (1 case). This last-mentioned eye had POAG and experienced IOP elevation within the first postoperative week, prompting filtration surgery; the eye underwent a second filtration surgery at 22 months postoperative (IOP was $24 \mathrm{mmHg}$ on maximal medications); final IOP in this eye was 11 mmHg. No stent-related issues were noted at any point. In the entire cohort, there were no reports of hypotony, intraocular inflammation, or choroidal hemorrhage or effusion during follow-up. Notably, this series included the surgeon's first experience with the device and a learning curve may have contributed to the mild complications observed early in the surgeon's experience.

Table 2 shows visual field and endothelial cell data at baseline, 12 months, and 24 months. The average VF MD was stable from preoperative $(-8.1 \mathrm{~dB})$ to 24 months postoperative $(-7.9)(\mathrm{p}=0.63$, not significant). The mean postoperative endothelial cell count remained within the expectations for cataract surgery alone, with a $3.6 \%$ 


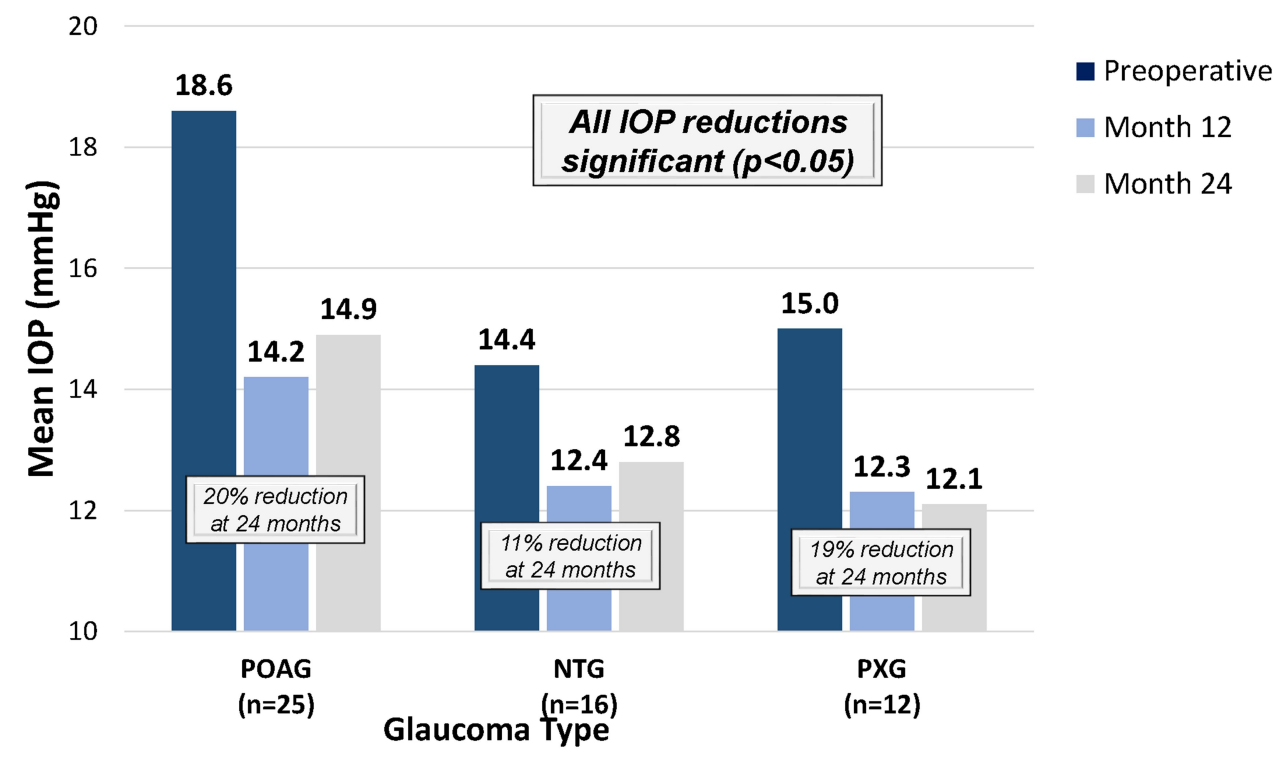

Figure 5 Mean intraocular pressure at 12 and 24 months vs preoperative*, by glaucoma subtype.

Abbreviations: IOP, intraocular pressure; POAG, primary open-angle glaucoma; NTG, normal-tension glaucoma; PXG, pseudoexfoliative glaucoma; *I POAG eye had filtration surgery at 3 weeks postoperative; subsequent IOP values are excluded from analysis above.

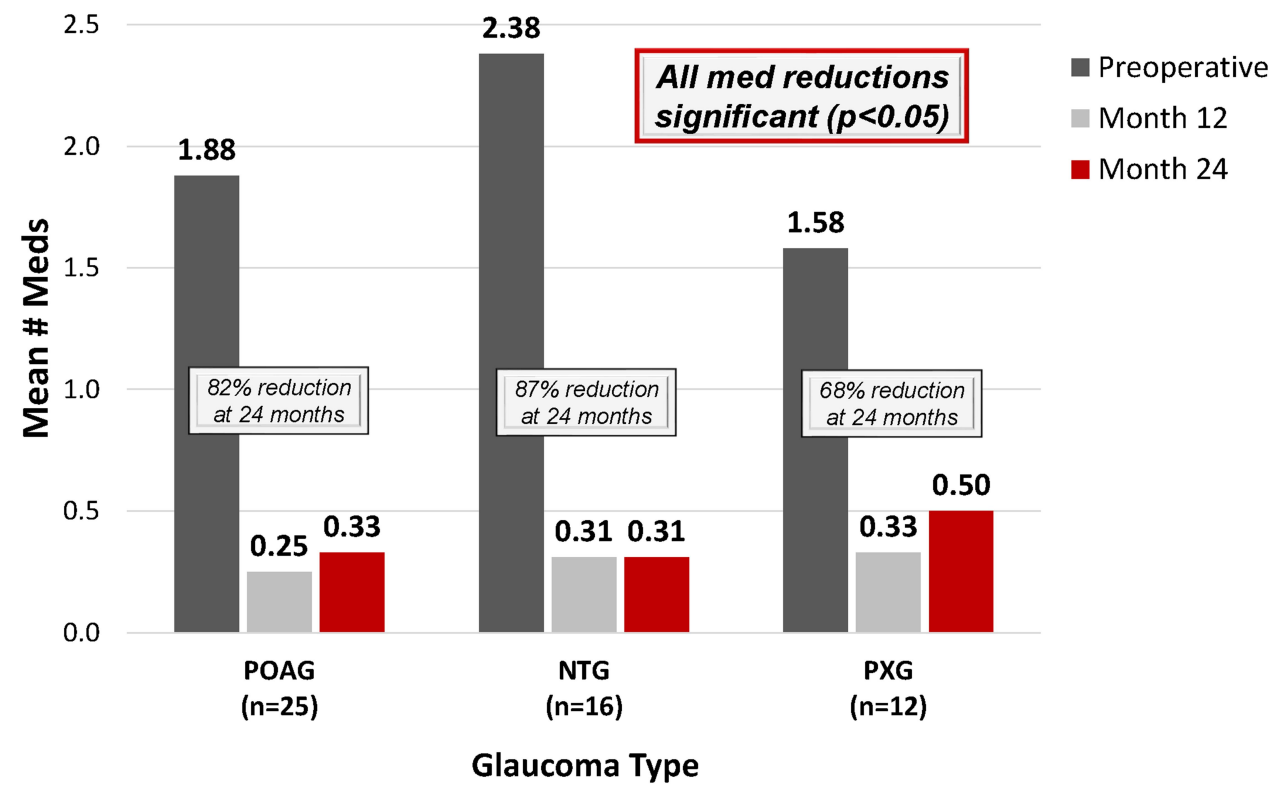

Figure 6 Mean number of medications at 12 and 24 months vs preoperative*, by glaucoma subtype.

Abbreviations: Meds, medications; POAG, primary open-angle glaucoma; NTG, normal-tension glaucoma; PXG, pseudoexfoliative glaucoma. *I POAG eye had filtration surgery at 3 weeks postoperative; subsequent medication values are excluded from analysis above.

decrease at 24 months postoperative versus baseline (2459 vs 2552 cells $/ \mathrm{mm}^{2}$ ).

\section{Discussion}

To date, the safety and performance of iStent trabecular micro-bypass have been established by a breadth of studies evaluating the device, including in standalone implantation or in combination with cataract surgery or other MIGS procedures, in both single- and multiple-stent usage, in populations with various levels of disease severity, and in various subtypes of glaucoma and ocular hypertension..$^{7-23}$ The stent has been widely adopted and studied by surgeons around the world. ${ }^{43}$ However, iStent outcomes have not been as closely examined in Japanese populations. One existing publication in a Japanese population is a 10patient case series by Shiba et al, which evaluated the 


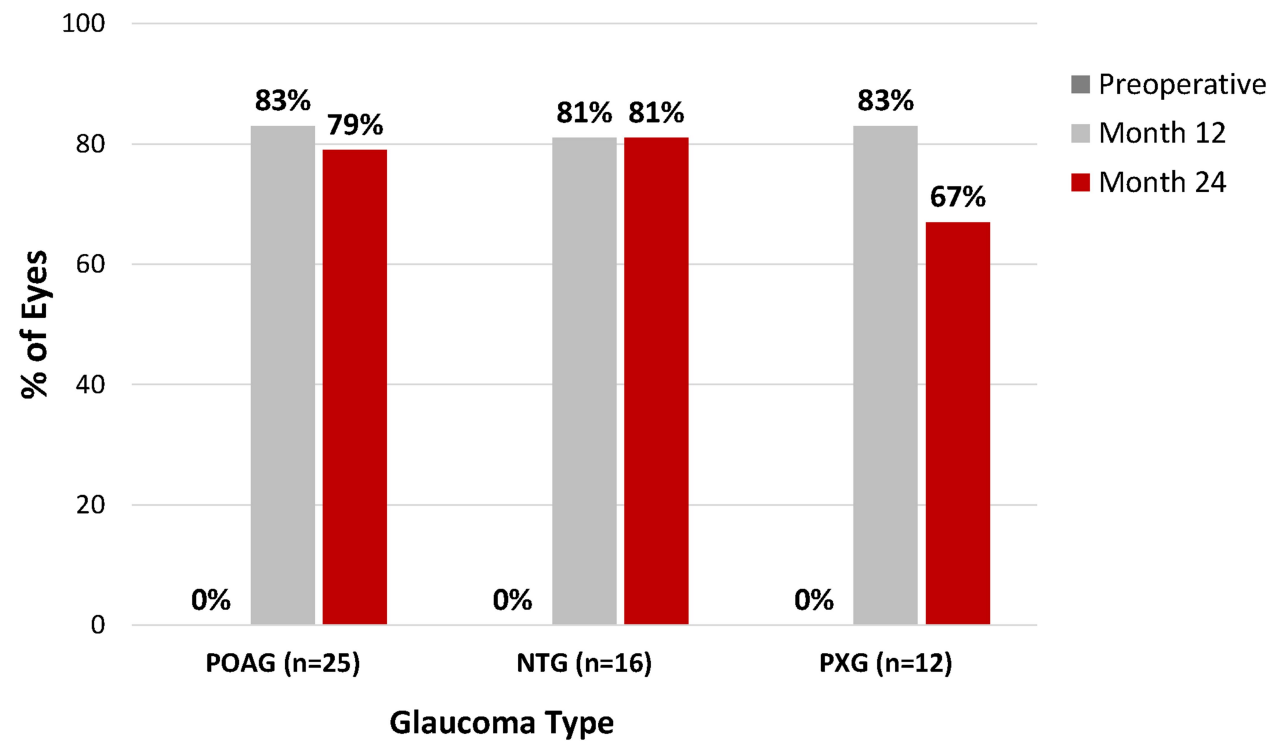

Figure 7 Proportional analysis of medication-free eyes preoperatively and at 12 and 24 months postoperative*, by glaucoma subtype.

Abbreviations: POAG, primary open-angle glaucoma; NTG, normal-tension glaucoma; PXG, pseudoexfoliative glaucoma. *I POAG eye had filtration surgery at 3 weeks postoperative; subsequent medication values are excluded from analysis above.

standalone implantation of 2 iStents in Japanese patients with uncontrolled POAG. ${ }^{23}$ The study showed promising outcomes (including IOP reduction from 22.0 to 16.9 $\mathrm{mmHg}$ at 6 months postoperative); however, the series did not include eyes with NTG or PXG, the modest sample size limits readers' ability to use the findings to guide treatment decisions, and it evaluated off-label usage of the device (ie, standalone implantation of 2 stents), which is not directly relevant to practicing clinicians. ${ }^{23}$

Table 2 Visual Field Mean Deviation and Endothelial Cell Density Through 24 Months Postoperative

\begin{tabular}{|c|c|c|c|}
\hline & Baseline & $\begin{array}{l}12 \\
\text { Months }\end{array}$ & $\begin{array}{l}24 \\
\text { Months }\end{array}$ \\
\hline \multicolumn{4}{|l|}{ VF MD } \\
\hline $\begin{array}{l}\mathrm{n} \text { with measurement } \\
\text { Mean VF MD }(\mathrm{dB}) \\
\mathrm{SD} \text { VF MD }(\mathrm{dB}) \\
\mathrm{p} \text {-value vs baseline }\end{array}$ & $\begin{array}{l}53 \\
-8.1 \\
4.6\end{array}$ & $\begin{array}{l}53 \\
-6.7 \\
4.6\end{array}$ & $\begin{array}{l}52^{\dagger} \\
-7.9 \\
5.1 \\
0.63\end{array}$ \\
\hline \multicolumn{4}{|l|}{ ECD } \\
\hline $\begin{array}{l}\mathrm{n} \text { with measurement } \\
\left.\text { Mean ECD (cells } / \mathrm{mm}^{2}\right) \\
\left.\text { SD ECD (cells } / \mathrm{mm}^{2}\right) \\
\% \text { ECD reduction vs } \\
\text { baseline }\end{array}$ & $\begin{array}{l}53 \\
2551.85 \\
234.74\end{array}$ & $\begin{array}{l}53 \\
2472.94 \\
284.86\end{array}$ & $\begin{array}{l}53 \\
2459.08 \\
408.05 \\
3.64 \%\end{array}$ \\
\hline
\end{tabular}

Note: ${ }^{\dagger} I$ patient was unable to complete $V F$ at 24 months due to dementia. Abbreviations: VF MD, visual field mean deviation; ECD, endothelial cell density; SD, standard deviation.
In addition to the limited data in Japanese populations, there is relatively sparse information on the role of MIGS procedures in NTG, which accounts for over $90 \%$ of OAG cases in Japanese individuals.

The present study addresses these gaps in clinical data by evaluating iStent trabecular micro-bypass stent implantation in combination with cataract surgery in a Japanese population, including in eyes with NTG. Taking into consideration the difficulty of treating NTG and the widely known risks of more aggressive filtering procedures, ${ }^{44,45}$ this report offers much-needed information on a minimally invasive surgical approach for treatment of Japanese patients and NTG patients.

Since this study population was composed entirely of eyes with medically controlled IOP, including in a subset of NTG patients, the baseline IOP was lower than that of many other published studies. Despite the well-known challenge of reducing such already-low IOPs, significant IOP reductions were achieved in this study, coupled with significant decreases in medication usage. In the overall cohort and the individual subgroups (POAG, NTG, PXG), mean IOP decreased by $11 \%$ to $20 \%$ (1.6 to $3.7 \mathrm{mmHg}$ ) versus baseline, a particularly meaningful finding considering that each $1 \mathrm{mmHg}$ reduction in IOP confers a $10 \%$ reduced risk of glaucoma progression. ${ }^{1}$ Meanwhile, mean medication burden decreased by $68-87 \%$ versus baseline. In addition, the proportion of eyes with IOP $\leq 15 \mathrm{mmHg}$ nearly doubled versus preoperative $(81 \%$ at 24 months versus $42 \%$ preoperatively). 
Consistent with prior studies evaluating IOP-lowering treatments, ${ }^{10,15-17,46,47}$ eyes with higher baseline IOP achieved a more robust postoperative IOP reduction than eyes with lower baseline IOP. Also consistent with prior MIGS studies, ${ }^{16,17,48}$ our data suggested a slight diminution of IOP- and medication-reducing effects after the first year postoperative. This is not unexpected, as stent implantation was accompanied by phacoemulsification, which is known to have mild ocular hypotensive effects (generally under $2 \mathrm{mmHg}$ ) in medically controlled glaucomatous eyes, and that these effects typically begin to diminish after the first year postoperative. ${ }^{46,47,49-53}$ Acknowledging this as a possibility, it is important and compelling that the two-year reductions are still significant in our cohort, including in all eyes and in the NTG subgroup, even after any possible post-phacoemulsification effects had begun to wane, and even in the setting of relatively low preoperative IOP. The sustained additional IOP reduction of stenting supports the premise that stentassociated IOP reduction can improve perfusion pressure, a pathophysiologic mechanism thought to be especially important in NTG patients.

The significant reduction in medication use in this study is particularly noteworthy, with dramatically increased percentage of eyes off medications after stenting. As standard clinical practice, the physician instructed all patients to stop their glaucoma medication immediately (within 24 hours) before surgery. Prior to this discontinuation, no eyes were medication-free. In contrast, $77 \%$ of eyes had eliminated medications by 24 months. In NTG eyes, in which medication reduction often is emphasized given their normal baseline IOP, medication burden was reduced by 2.37 medications (87\%) and drops were eliminated entirely in $81 \%$ of eyes. This medication reduction is greater than what was previously reported for NTG eyes after cataract surgery alone (0.82medication reduction). ${ }^{54}$ Given the recognized side effects, ocular surface toxicity, costs, and diminished quality of life associated with long-term use of topical medications, the decrease in medications is meaningful for patients as well as clinicians. ${ }^{55-60}$

The safety profile in this study was favorable. There were no intraoperative complications and no cases of severe postoperative adverse events. Adverse events were managed and incurred no sequelae. Visual fields were stable over time, and endothelial cell counts remained within the range expected after cataract surgery alone. In addition, only one eye $(1.9 \%$ of the cohort $)$ had a secondary glaucoma surgery for continued IOP elevation in the 2-year postoperative period. Together with the previously discussed efficacy outcomes of reduced IOP and medications, the favorable safety profile presents a positive benefit-to-risk ratio that may be appropriate even for patients earlier in the disease process than those in the present study - for example, in patients with lower levels of VF compromise (vs the VF MD of -8.1 in our cohort) or those with clear lens needing standalone surgery.

Although the inclusion of a control group was outside the scope of this retrospective case series, the study results can be evaluated alongside prior data on postphacoemulsification outcomes in glaucomatous eyes. Phacoemulsification is known to mildly reduce IOP, with postoperative reductions being proportional to preoperative IOP, and with effects usually beginning to fade after the first year postoperative. ${ }^{46,47,49-53}$ In a study by Poley et al, for example, glaucomatous eyes with preoperative IOP of $15-17 \mathrm{mmHg}$ experienced a $1.1-\mathrm{mmHg}$ postphacoemulsification IOP reduction, while eyes in the 5-14 mmHg group actually increased by $1.7 \mathrm{mmHg}{ }^{46}$ These values can be compared with the 2.9-mmHg reduction observed in our overall cohort with preoperative IOP of $16.5 \mathrm{mmHg}$, and the $1.6-\mathrm{mmHg}$ decrease in our NTG subgroup with preoperative IOP of $14.4 \mathrm{mmHg}$. In a more recent study by Baek et al, ${ }^{53}$ subgroup analysis of NTG eyes showed a $0.78 \mathrm{mmHg}$ IOP reduction, which also was less than our NTG subgroup. In addition, neither study takes into consideration the value of the concomitant 2.37medication decrease experienced by our NTG patients (versus the aforementioned 0.82-medication reduction reported for NTG eyes after cataract surgery alone), ${ }^{54}$ or the 1.59-medication decrease experienced by our overall cohort. Finally, the IOP and medication reductions in our overall cohort as well as all subgroups remained significant through 2 years, even after phacoemulsificationassociated IOP effects would be expected to wane.

This study had limitations including no control group (as discussed above), modest sample size, single site, and no preoperative medication washout phase. The study followed standard Japanese guidelines for iStent usage, but did not employ additional exclusion or inclusion criteria such as those seen in some clinical trials, as it was drawn from a typical clinician's patient population. The retrospective study design allows for the possibility of missing follow-up data at the specific time points designated for the study. Although 2-year data are robust and 
valuable, ongoing follow-up and prospective inclusion of a phacoemulsification-only control group are promising possibilities for future evaluations of further longitudinal performance and safety.

Despite these acknowledged limitations, the results of this study are compelling, particularly because of the limited existing data on the device in both Japanese glaucoma patients as well as those with NTG. In addition, the data are representative of a real-world patient population, thereby enhancing generalizability to other practicing surgeons.

\section{Conclusion}

To our knowledge, this is the first published report exclusively evaluating the trabecular micro-bypass stent with cataract surgery in a Japanese population with medically controlled IOP. In addition, the report includes subgroup analyses for eyes with NTG and PXG, populations that have been less extensively studied with respect to MIGS procedures. These subgroups had similarly favorable outcomes as the overall cohort. The findings corroborate prior research on the use of iStent in predominantly POAG populations, and augment currently available data on NTG and PXG patients. Findings suggest that this microinvasive treatment modality may provide an appealing treatment alternative for patients hoping to reduce their IOP and topical medication regimen while also avoiding the risks associated with filtering procedures.

\section{Compliance with Ethics Guidelines}

Ethics Committee approval was obtained from the Institutional Review Board (IRB) of the Fukui-ken Saiseikai Hospital (Fukui, Japan). All procedures performed were in accordance with the 1964 Declaration of Helsinki and its later amendments or comparable ethical standards. Informed consent was obtained from all participants.

\section{Acknowledgments}

We thank the patients in this study.

\section{Author Contributions}

All authors made a significant contribution to the work reported, whether that is in the conception, study design, execution, acquisition of data, analysis and interpretation, or in all these areas; took part in drafting, revising or critically reviewing the article; gave final approval of the version to be published; have agreed on the journal to which the article has been submitted; and agree to be accountable for all aspects of the work.

\section{Funding}

No funding was provided for the work in this study. Editorial assistance and publication fees were provided by Glaukos Corporation (San Clemente, CA, USA).

\section{Disclosure}

The authors report no conflicts of interest.

\section{References}

1. Heijl A, Leske MC, Bengtsson B, et al. Reduction of intraocular pressure and glaucoma progression: results from the early manifest glaucoma trial. Arch Ophthalmol. 2002;120(10):1268-1279. doi:10. 1001/archopht.120.10.1268

2. Kass MA, Heuer DK, Higginbotham EJ, et al. The ocular hypertension treatment study: a randomized trial determines that topical ocular hypotensive medication delays or prevents the onset of primary open-angle glaucoma. Arch Ophthalmol. 2002;120:701-713. doi:10.1001/archopht.120.6.701

3. Sommer A, Tielsch JM, Katz J, et al. Relationship between intraocular pressure and primary open angle glaucoma among white and black Americans: the baltimore eye survey. Arch Ophthalmol. 1991;109:1090-1095. doi:10.1001/archopht.1991.01 080080050026

4. Mitchell P, Smith W, Attebo K, Healey PR. Prevalence of open-angle glaucoma in Australia: the blue mountains eye study. Ophthalmology. 1996;103:1661-1669. doi:10.1016/S0161-6420 (96)30449-1

5. Collaborative Normal-Tension Glaucoma Study Group. Comparison of glaucomatous progression between untreated patients with normal-tension glaucoma and patients with therapeutically reduced intraocular pressures. Am J Ophthalmol. 1998;126:487-497. doi:10.1016/S0002-9394(98)00223-2

6. Saheb H, Ahmed I. Micro-invasive glaucoma surgery: current perspectives and future directions. Curr Opin Ophthalmol. 2012;23 (2):96-104. doi:10.1097/ICU.0b013e32834ffle7

7. Samuelson TW, Katz LJ, Wells JM, Duh Y-J, Giamporcaro JE. Randomized evaluation of the trabecular micro-bypass stent with phacoemulsification in patients with glaucoma and cataract. Ophthalmology. 2011;118(3):459-467. doi:10.1016/j.ophtha.2010.07. 007

8. Fea AM, Consolandi G, Zola M, et al. Micro-bypass implantation for primary open-angle glaucoma combined with phacoemulsification: 4-year follow-up. J Ophthalmol. 2015;795357.

9. Belovay GW, Naqi A, Chan BJ, Rateb M, Ahmed IIK. Using multiple trabecular micro-bypass stents in cataract patients to treat open-angle glaucoma. J Cataract Refract Surg. 2012;38(11): 1911-1917. doi:10.1016/j.jcrs.2012.07.017

10. Berdahl JP, Dockter Z, Schweitzer J, Ibach M, Ferguson T Long-term evaluation of a trabecular microbypass stent with cataract surgery in open-angle glaucoma: 7-year results. Presentation at the Virtual Annual Meeting of the American Society of Cataract and Refractive Surgery (ASCRS): Boston, MA; May 16, 2020.

11. Chen DZ, Sng CCA, Sangtam T, et al. Phacoemulsification vs phacoemulsification with micro-bypass stent implantation in primary angle closure and primary angle closure glaucoma: A randomized single-masked clinical study. Clin Exp Ophthalmol. 2020;48 (4):450-461. doi:10.1111/ceo.13721 
12. Neuhann TH, Hornbeak DM, Neuhann RT, Giamporcaro JE. Longterm effectiveness and safety of trabecular micro-bypass stent implantation with cataract surgery in patients with glaucoma or ocular hypertension: 5-year outcomes. J Cataract Refract Surg. 2019;45(3):312-320. doi:10.1016/j.jcrs.2018.10.029

13. Gallardo MJ, Supnet RA. Three-year outcomes of combined trabecular micro-bypass and phacoemulsification in a predominantly Hispanic population with primary open-angle glaucoma. Clin Ophthalmol. 2019;13:869-879. doi:10.2147/OPTH.S189071

14. Chang DF, Donnenfeld ED, Katz LJ, et al. Efficacy of two trabecular micro-bypass stents combined with topical travoprost in open-angle glaucoma not controlled on two preoperative medications: 3-year follow-up. Clin Ophthalmol. 2017;11:523-528. doi:10.2147/OPTH. $\mathrm{S} 121041$

15. Ferguson TJ, Berdahl JP. Schweitzer JA and Sudhagoni RG. Clinical evaluation of a trabecular micro-bypass stent with phacoemulsification in patients with open-angle glaucoma and cataract. Clin Ophthalmol. 2016;10:1767-1773. doi:10.2147/OPTH.S114306

16. Ferguson T, Swan R, Ibach M, Schweitzer J, Sudhagoni R, Berdahl JP. Evaluation of a trabecular microbypass stent with cataract extraction in severe primary open-angle glaucoma. $J$ Glaucoma. 2018;27(1):71-76. doi:10.1097/IJG.0000000000000825

17. Ferguson TJ, Swan RJ, Bleeker A, et al. Trabecular microbypass stent implantation in pseudoexfoliative glaucoma: long-term results [published online ahead of print, 2020 May 7]. J Cataract Refract Surg. 2020. doi: $10.1097 /$ j.jcrs. 0000000000000243

18. Ferguson TJ, Ibach M, Schweitzer J, Karpuk KL, Stephens JD, Berdahl JP. Trabecular microbypass stent implantation with cataract extraction in pigmentary glaucoma. Clin Exp Ophthalmol. 2020;48 (1):37-43. doi:10.1111/ceo.13638

19. Ferguson TJ, Ibach M, Schweitzer J, et al. Trabecular microbypass stent implantation in pseudophakic eyes with open-angle glaucoma: long-term results. J Cataract Refract Surg. 2019;45(4):414-420. doi:10.1016/j.jcrs.2018.11.005

20. Fechtner RD, Voskanyan L, Vold SD, et al. Five-year, prospective, randomized, multi-surgeon trial of two trabecular bypass stents versus prostaglandin for newly-diagnosed open-angle glaucoma. Ophthalmology Glaucoma. 2019;2(3):156-166. doi:10.1016/j.ogla.20 19.03.004

21. El Wardani M, Bergin C, Achache F, Sharkawi E. Evaluating the trabecular micro-bypass stent combined with phacoemulsification compared to phacoemulsification alone. Klin Monbl Augenheilkd. 2015;232(4):442-445. doi:10.1055/s-0035-1545798

22. Craven ER, Katz LJ, Wells JM, Giamporcaro JE. Cataract surgery with trabecular micro- bypass stent implantation in patients with mild-to-moderate open-angle glaucoma and cataract: two-year follow-up. J Cataract Refract Surg. 2012;38:1339-1345. doi:10.10 16/j.jcrs.2012.03.025

23. Shiba D, Hosoda S, Yaguchi S, Ozeki N, Yuki K, Tsubota K. Safety and efficacy of two trabecular micro-bypass stents as the sole procedure in japanese patients with medically uncontrolled primary open-angle glaucoma: a pilot case series. $J$ Ophthalmol. 2017;2017:9605461. doi:10.1155/2017/9605461

24. Neuhann R, Neuhann T. Second-generation trabecular micro-bypass stent implantation: retrospective analysis after 12- and 24-month follow-up. Eye Vis. 2020;7(1):1. doi:10.1186/s40662-019-0169-7

25. Salimi A, Clement C, Shiu M, Harasymowycz P. Second-generation trabecular micro-bypass (iStent inject) with cataract surgery in eyes with normal-tension glaucoma: one-year outcomes of a multi-centre study [published online ahead of print, $2020 \mathrm{Jul} 1$ 1]. Ophthalmol Ther. 2020. doi:10.1007/s40123-020-00266-6

26. Clement CI, Howes F, Ioannidis AS, Shiu M, Manning D. One-year outcomes following implantation of second-generation trabecular micro-bypass stents in conjunction with cataract surgery for various types of glaucoma or ocular hypertension: multicenter, multi-surgeon study. Clin Ophthalmol. 2019;13:491-499. doi:10.2147/OPTH.S187272
27. Samuelson TW, Sarkisian SR Jr, Lubeck DM, et al. for the iStent inject study group. Prospective, randomized, controlled pivotal trial of iStent inject trabecular micro-bypass in primary open-angle glaucoma and cataract: two-year results. Ophthalmology. 2019;126 (6):811-821. doi:10.1016/j.ophtha.2019.03.006

28. Salimi A, Lapointe J, Harasymowycz P. One-year outcomes of second-generation trabecular micro-bypass stents (iStent inject) implantation with cataract surgery in different glaucoma subtypes and severities. Ophthalmol Ther. 2019;8(4):563-575. doi:10.1007/ s40123-019-00214-z

29. Manning D. Real-world case series of iStent or iStent inject trabecular micro-bypass stents combined with cataract surgery. Ophthalmol Ther. 2019;8(4):549-561. doi:10.1007/s40123-019-00208-x

30. Guedes RAP, Gravina DM, Lake JC, Guedes VMP, Chaoubah A. One-year comparative evaluation of iStent or iStent inject implantation combined with cataract surgery in a single center. Adv Ther. 2019;36(10):2797-2810. doi:10.1007/s12325-019-01067-5

31. Ferguson TJ, Dockter Z, Bleeker A, et al. iStent inject trabecular microbypass stent implantation with cataract extraction in open-angle glaucoma: early clinical experience. Eye Vis. 2020;7:28. doi:10.1186/ s40662-020-00194-3

32. Hengerer FH, Auffarth GU, Riffel C, Conrad-Hengerer I. Prospective, non-randomized, 36-month study of second-generation trabecular micro-bypass stents with phacoemulsification in various types of glaucoma. Ophthalmol Ther. 2018;7(2):405-415. doi:10. 1007/s40123-018-0152-8

33. Hengerer FH, Auffarth GU, Riffel C, Conrad-Hengerer I. Secondgeneration trabecular micro-bypass stents as standalone treatment for glaucoma: a 36-month prospective study. Adv Ther. 2019;36 (7):1606-1617. doi:10.1007/s12325-019-00984-9

34. Berdahl J, Voskanyan L, Myers JS, Katz LJ, Samuelson TW. iStent inject trabecular micro-bypass stents with topical prostaglandin as standalone treatment for open-angle glaucoma: 4-year outcomes. Clin Exp Ophthalmol. 2020;48:767-774. doi:10.1111/ceo.13763

35. Fea AM, Belda JI, Rekas M, et al. Prospective unmasked randomized evaluation of the iStent inject versus two ocular hypotensive agents in patients with primary open-angle glaucoma. Clin Ophthalmol. 2014;8:875-882.

36. Klamann MKJ, Gonnermann J, Pahlitzsch M, et al. iStent inject in phakic open angle glaucoma. Graefes Arch Clin Exp Ophthalmol. 2015;253(6):941-947. doi:10.1007/s00417-015-3014-2

37. Lindstrom R, Sarkisian SR, Lewis R, Hovanesian J, Voskanyan L. Four-year outcomes of two second-generation trabecular micro-bypass stents in patients with open-angle glaucoma on one medication. Clin Ophthalmol. 2020;14:71-80. doi:10.2147/OPTH. S235293

38. Voskanyan L, Garcia-Feijoo J, Belda JI, Fea A, Junemann A, Baudouin C. Prospective, unmasked evaluation of the iStent inject system for open-angle glaucoma: synergy trial. Adv Ther. 2014;31 (2):189-201. doi:10.1007/s12325-014-0095-y

39. Arriola-Villalobos P, Martinez-de-la-Casa JM, Diaz-Valle D, Morales-Fernandez L, Fernandez-Perez C, Garcia-Feijoo J. Glaukos iStent inject ${ }^{\circledR}$ trabecular micro-bypass implantation associated with cataract surgery in patients with coexisting cataract and open-angle glaucoma or ocular hypertension: a long-term study. J Ophthalmol. 2016;2016:1056573. doi:10.1155/2016/1056573

40. Ioannidis AS, Toteberg-Harms M, Hamann T, Hodge C. Refractive outcomes after trabecular micro-bypass stents (iStent inject) with cataract extraction in open-angle glaucoma. Clin Ophthalmol. 2020;14:517-524. doi:10.2147/OPTH.S239103

41. Iwase A, Suzuki Y, Araie M, et al. The prevalence of primary open-angle glaucoma in Japanese: the Tajimi Study. Ophthalmology. 2004;111 (9):1641-1648.

42. Sultan M, Blondeau P. Episcleral venous pressure in younger and older subjects in the sitting and supine positions. J Glaucoma. 2003;12(4):370. doi:10.1097/00061198-200308000-00013 
43. Lavia C, Dallorto L, Maule M, Ceccarelli M, Fea AM. Minimallyinvasive glaucoma surgeries (MIGS) for open angle glaucoma: A systematic review and meta-analysis. Virgili Ged. PLoS One. 2017;12(8):e0183142. doi:10.1371/journal.pone.0183142

44. Jampel HD, Musch DC, Gillespie BW, Lichter PR, Wright MM, Guire KE. Collaborative initial glaucoma treatment study group. collaborative initial glaucoma treatment study group. Perioperative complications of trabeculectomy in the collaborative initial glaucoma treatment study (CIGTS). Am J Ophthalmol. 2005;140(1):16-22. doi:10.1016/j.ajo.2005.02.013

45. Gedde SJ, Herndon LW, Brandt JD, Budenz DL, Feuer WJ, Schiffman JC. Tube versus trabeculectomy study group. Postoperative complications in the Tube Versus Trabeculectomy (TVT) study during five years of follow-up. Am J Ophthalmol. 2012;153:804-814. doi:10.1016/j.ajo.2011.10.024

46. Poley BJ, Lindstrom RL, Samuelson TW, Schulze R Jr. Intraocular pressure reduction after phacoemulsification with intraocular lens implantation in glaucomatous and nonglaucomatous eyes: evaluation of a causal relationship between the natural lens and open-angle glaucoma. J Cataract Refract Surg. 2009;35(11):1946-1955. doi:10. 1016/j.jcrs.2009.05.061

47. Shingleton BJ, Gamell LS, O’Donoghue MW, Baylus SL, King R. Long-term changes in intraocular pressure after clear corneal phacoemulsification: normal patients versus glaucoma suspect and glaucoma patients. J Cataract Refract Surg. 1999;25(7):885-890. doi:10. 1016/S0886-3350(99)00107-8

48. for the HORIZON Investigators, Samuelson TW, Chang DF, Marquis R, et al. A Schlemm canal microstent for intraocular pressure reduction in primary open-angle glaucoma and cataract: the horizon study. Ophthalmology. 2019;126(1):29-37. doi:10.1016/j. ophtha.2018.05.012.

49. Handa J, Henry JC, Krupin T, et al. Extracapsular cataract extraction with posterior chamber lens implantation in patients with glaucoma. Arch Ophthalmol. 1987;105:765-769. doi:10.1001/archopht.1987.01 060060051031

50. Kim DD, Doyle WJ, Smith FM. Intraocular pressure reduction phacoemulsification cataract extraction with posterior chamber lens implantation in glaucoma patients. Ophthalmic Surg Lasers. 1999;30:37-40.
51. Mathalone N, Hyams M, Neiman S, et al. Long-term intraocular pressure control after clear corneal phacoemulsification in glaucoma patients. J Cataract Refract Surg. 2005;31:479-483. doi:10.1016/j. jcrs.2004.06.046

52. Cinotti DJ, Fiore PM, Maltzman BA, et al. Control of intraocular pressure in glaucomatous eyes after extracapsular cataract extraction with intraocular lens implantation. $J$ Cataract Refract Surg. 1987;14:650-653. doi:10.1016/S0886-3350(88)80033-6

53. Baek SU, Kwon S, Park IW, Suh W. Effect of phacoemulsification on intraocular pressure in healthy subjects and glaucoma patients. J Korean Med Sci. 2019;34(6):e47. doi:10.3346/jkms.2019.34.e47

54. Lee W, Bae HW, Kim CY, Seong GJ. The change of anterior segment parameters after cataract surgery in normal-tension glaucoma. Int J Ophthalmol. 2017;10(8):1239-1245.

55. Fechtner RD, Godfrey DG, Budenz D, Stewart JA, Stewart WC, Jasek MC. Prevalence of ocular surface complaints in patients with glaucoma using topical intraocular pressure-lowering medications. Cornea. 2010;29(6):618-621. doi:10.1097/ICO.0b013e3181c325b2

56. Baudouin C, Labbé A, Liang H, Pauly A, Brignole-Baudouin F. Preservatives in eyedrops: the good, the bad and the ugly. Prog Retin Eye Res. 2010;29(4):312-334. doi:10.1016/j.preteyeres.2010. 03.001

57. Leung EW, Medeiros FA, Weinreb RN. Prevalence of ocular surface disease in glaucoma patients. J Glaucoma. 2008;17(5):350-355. doi:10.1097/IJG.0b013e31815c5f4f

58. Inoue K. Managing Adverse effects of glaucoma medications. Clin Ophthalmol. 2014;8:903-913. doi:10.2147/OPTH.S44708

59. Ngan K, Fraser E, Buller S, Buller A. A cost minimisation analysis comparing iStent accompanying cataract surgery and selective laser trabeculoplasty versus topical glaucoma medications in a public healthcare setting in New Zealand. Graefes Arch Clin Exp Ophthalmol. 2018;256(11):2181-2189. doi:10.1007/s00417018-4104-8

60. Berdahl JP, Khatana AK, Katz LJ, et al. Cost-comparison of two trabecular micro-bypass stents versus selective laser trabeculoplasty or medications only for intraocular pressure control for patients with open-angle glaucoma. J Med Econ. 2017;20(7):760-766. doi:10.10 $80 / 13696998.2017 .1327439$
Clinical Ophthalmology

\section{Publish your work in this journal}

Clinical Ophthalmology is an international, peer-reviewed journal covering all subspecialties within ophthalmology. Key topics include: Optometry; Visual science; Pharmacology and drug therapy in eye diseases; Basic Sciences; Primary and Secondary eye care; Patient Safety and Quality of Care Improvements. This journal is indexed on PubMed
Dovepress

Central and CAS, and is the official journal of The Society of Clinical Ophthalmology (SCO). The manuscript management system is completely online and includes a very quick and fair peer-review system, which is all easy to use. Visit http://www.dovepress.com/ testimonials.php to read real quotes from published authors. 